\title{
A randomised double-blind placebo-controlled phase II study of AGI004 for control of chemotherapy-induced diarrhoea
}

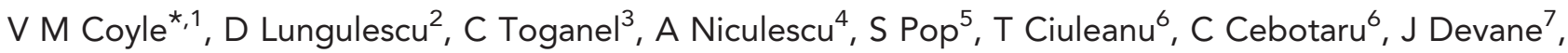 \\ $\mathrm{M} \mathrm{Martin}^{7}$ and R H Wilson ${ }^{8}$ \\ ${ }^{1}$ NI Cancer Centre, Belfast City Hospital, Lisburn Road, Belfast BT9 7AB, UK.; ${ }^{2}$ Meditech Orizont Clinic Craiova, Miron Costin \\ Street, No. 1, 200642 Craiova, Romania; ${ }^{3}$ County Hospital Tg-Mures, Gheorghe Marinescu Street, No. 3, Tg-Mures, Romania; \\ ${ }^{4}$ Oncomed SRL Timisoara, Ciprian Porumbescu, No. 59, Timisoara, Romania; ${ }^{5}$ County Hospital Satu-Mare, P-ta Eroilor Revolutiei, \\ No. 1-2, 440056 Satu-Mare, Romania; ${ }^{6}$ Oncologic Institute Prof. Dr. I Chiricuta, Republicii St. 34-36, 400015 Cluj-Napoca, Romania; \\ ${ }^{7}$ AGI Therapeutics Research Ltd, Adelaide Chambers, Peter Street, Dublin 8, Ireland and ${ }^{8}$ Centre for Cancer Research and Cell \\ Biology, Queens University Belfast, Lisburn Road, Belfast BT9 7BL, UK
}

Background: AGI004 is a controlled-release transdermal patch preparation of mecamylamine. We conducted a randomised placebo-controlled phase II study of two dose levels of AGI004 in chemotherapy-induced diarrhoea (CID).

Methods: Adult patients receiving chemotherapy who had experienced diarrhoea ( $\mathrm{NCl}$ grade 1-2) during previous cycles of chemotherapy were eligible. In all, 64 patients were randomised to receive AGI004 $4 \mathrm{mg}$ then $8 \mathrm{mg}$ per $24 \mathrm{~h}$ transdermal patch or placebo for two sequential cycles of chemotherapy. Patients' severity of diarrhoea was physician-assessed using $\mathrm{NCl}$ grade of diarrhoea and patient-assessed using information recorded in daily diaries of bowel movements.

Results: Overall AGI004 doubled the odds of a response to treatment on the first day of chemotherapy based on physician assessment of $\mathrm{NCl}$ grade of diarrhoea compared with placebo (odds ratio $=2.0,90 \%$ confidence interval: $0.9-4.5$ ) and there was a trend to improved response rates for AGI004 for the full treatment cycle although these results were not statistically significant. There was also evidence of significantly improved response rates based on patient assessment of diarrhoea both overall $(P=0.05)$ and at the 8-mg dose level $(P=0.02)$ compared with placebo.

Conclusion: AGI004 demonstrated effectiveness in reducing chemotherapy-associated diarrhoea, with results suggesting response across multiple measurements of diarrhoea. Treatment was well tolerated with no drug-related adverse events. Further evaluation of this agent in the management of CID is warranted.

Chemotherapy-induced diarrhoea (CID) is a common complication of cancer treatment causing effects ranging from troublesome to life threatening. The incidence of CID is variable, occurring at any severity in $40-80 \%$ of patients receiving irinotecan, fluorouracil, capecitabine or oxaliplatin alone or in combination (Leichman et al, 1995; Giacchetti et al, 2000; Saltz et al, 2000; Van Cutsem et al, 2000). Severe diarrhoea (NCI CTC v3.0 grade 3 or 4 ) occurs less frequently but has been reported at rates of up to $31 \%$ in patients receiving irinotecan (Saltz et al, 2000) with consequent dose reduction or delay or, more worryingly, resulting in cessation 
of treatment or patient mortality (Rothenberg et al, 2001). Attempts to identify biomarkers predictive of gastrointestinal toxicity following treatment with these agents have not yielded consistent results (Braun et al, 2009; Boige et al, 2010; McLeod et al, 2010); hence, patients receiving these agents do not routinely undergo pharmacogenetic testing currently but are counselled about the risk of CID and the need for prompt treatment in the event of this occurring.

The mechanism of CID is not completely understood but is thought to be a multifactorial process. Chemotherapy causes direct toxic effects on proliferating epithelial crypt cells resulting in disruption of the mucosal barrier (Duncan and Grant, 2003) and impaired absorption of electrolytes and water from the gut lumen resulting in diarrhoea. There is also altered enzyme secretion and changes in gut motility causing a reduction in transit time (Gibson and Keefe, 2006). Management of CID generally involves use of anti-diarrhoeal rescue medication, with use of opioids such as loperamide considered standard first-line treatment agents alongside supportive measures such as hydration (Benson et al, 2004). Loperamide acts as a $\mu$-opioid receptor agonist in the intestine, but not centrally, reducing gastrointestinal motility and increasing water reabsorption and has been shown to be an effective treatment in the initial management of CID, but less effective in controlling severe diarrhoea (Cascinu et al, 2000). In this setting the somatostatin analogue octreotide, which exerts its antidiarrhoeal effects by decreasing gastrointestinal hormone secretion, reducing intestinal mobility and increasing water reabsorption, has demonstrated efficacy in controlling even severe or persistent CID (Goumas et al, 1998; Barbounis et al, 2001; Szilagyi and Shrier, 2001). This is clearly an effective agent for treatment of CID; however, it requires repeated parenteral administration in view of its short half life and is relatively expensive.

Although the management of CID is well described, pharmacological approaches for its prevention are lacking, with a limited number of studies addressing this issue. Given the effectiveness of octreotide in controlling established CID use of this agent in the preventative setting has been investigated, but with disappointing results. Meropol et al (1998) aimed to use octreotide prophylaxis as a means of potentially increasing dose intensity but found no additional benefit in the addition of subcutaneous octreotide for the duration of chemotherapy in preventing CID in patients receiving weekly 5 -fluorouracil with high-dose leucovorin and consequently were unable to escalate treatment doses as planned.

The development of a long-acting slow-release formulation of octreotide that was effective in controlling diarrhoea associated with carcinoid syndrome merited further investigation in CID prevention. In the STOP study, 147 patients were randomised to receive one of two dose levels ( 30 or $40 \mathrm{mg}$ ) of long-acting octreotide prior to chemotherapy with less severe diarrhoea and less need for supportive measures for management of CID observed in the higher dose level although the differences were not statistically significant (Rosenoff et al, 2006). However, the use of prophylactic long-acting octreotide was not effective in preventing chemoradiotherapy-induced diarrhoea in patients with rectal cancer (Zachariah et al, 2010).

Similarly, the use of other oral pharmacological agents that have demonstrated effectiveness and safety in the management of infective diarrhoea, such as eracecadotril, have also been disappointing when used in the setting of prevention of CID (Ychou et al, 2000). Other therapeutic measures that have been evaluated in CID prevention have shown perhaps more potential such as use of activated charcoal (AC) or alkalinisation of the gastrointestinal tract.

In a phase II study evaluating the benefit of irinotecan therapy in patients with advanced colorectal cancer, a subset received prophylactic AC with their first cycle of chemotherapy but not with the second and subsequent cycles; administration of $\mathrm{AC}$ during cycle 1 was associated with a reduced incidence of grade 3 or 4 diarrhoea and reduced use of rescue loperamide relative to the second cycle of treatment however given the small number of patients included in this formal statistical analysis was not performed (Michael et al, 2004). A further small prospective study of $\mathrm{AC}$ in children receiving irinotecan chemotherapy $(n=22)$ demonstrated a significant reduction in grade 3 and 4 diarrhoea and improved compliance with treatment (Sergio et al, 2008).

Oral alkalisation of the gastrointestinal tract has also been reported to have a beneficial effect in preventing delayed diarrhoea in patients receiving irinotecan-containing chemotherapy (Takeda et al, 2001; Valenti Moreno et al, 2006), but again these studies have also been limited by small sample size and the possibility that this approach alters the pharmacokinetics of irinotecan in vivo (Hamada et al, 2005).

The anti-hypertensive agent mecamylamine exerts its hypotensive effect by ganglion blockade, with side effects at antihypertensive doses resulting from parasympathetic inhibition (Papke et al, 2001). At lower doses, it crosses the blood-brain barrier acting as a cholinergic antagonist to neuronal nicotinic receptors, prompting its evaluation in smoking cessation and substance abuse studies (Young et al, 2001). Studies evaluating this agent in smoking cessation have reported constipation as a side effect but otherwise good tolerability (Rose et al, 1994). At low doses, mecamylamine has selective antagonistic activity on nicotinic acetylcholine receptor (nAChR) subtypes predominantly found on enteric neurons. AGI004 is a controlled-release transdermal patch preparation of mecamylamine administered once daily that achieves these enteric neuronal effects without broad non-enteric anti-cholinergic effects. In smoking cessation studies AGI004 is associated with constipation, which is a dosedependent side effect, but is otherwise well tolerated. Similarly, clinical experience in functional diarrhoea confirms AGI004 is well tolerated and associated with improvement in stool consistency. In view of the alterations in gut motility and imbalance between absorption and secretion observed in CID and the previously described role of $\mathrm{nAChR}$ in modulating gut motility and secretory effects (Furness and Sanger, 2002) AGI004 was investigated as a novel agent for CID prevention.

\section{MATERIALS AND METHODS}

This study was a randomised, prospective, multi-centre, doubleblind, placebo-controlled phase II study of two dose levels of transdermal mecamylamine to determine the efficacy of transdermal mecamylamine in the control of CID across seven sites in Europe. The study was conducted in accordance with the Declaration of Helsinki and Good Clinical Practice Guidelines and was approved by the relevant ethics committees. All patients gave informed consent for entry into the study.

Eligibility criteria. Eligible patients were those age 18 years and over who were receiving chemotherapy associated with a high likelihood of diarrhoea and who had experienced diarrhoea during previous cycles of chemotherapy. This included patients with colorectal cancer receiving a fluoropyrimidine (fluorouracil or capecitabine) as monotherapy or in combination with irinotecan or oxaliplatin, patients with breast cancer receiving capecitabine and patients with upper gastrointestinal cancers receiving cisplatin/ fluorouracil, epirubicin/ cisplatin/fluorouracil or epirubicin/oxaliplatin/fluorouracil chemotherapy. Patients had to have active diarrhoea of NCI CTC v3.0 grade 1 or 2, as graded by the physician, with no significant complicating factors to be eligible for randomisation. Eligible patients also must have had at least two further treatment cycles planned. Patients with pre-existing 
diarrhoea, ileostomy/colostomy or any co-existing gastrointestinal conditions were excluded.

Treatment plan. Prior to study entry, eligible patients had received at least one cycle of chemotherapy, and experienced NCI grade I or II diarrhoea during this cycle. After inclusion in the study, patients were randomised to receive treatment with transdermal mecamylamine (AGI004) $4 \mathrm{mg}$ per $24 \mathrm{~h}$ or placebo prior to initiation of chemotherapy. Placebo was delivered using an identical looking patch to the active agent. The patch was applied $24 \mathrm{~h}$ prior to chemotherapy to ensure plasma mecamylamine levels were attained prior to chemotherapy to allow evaluation of efficacy in the acute phase (first day of chemotherapy). The patch was applied daily thereafter for the duration of the treatment cycle to ensure study drug was received throughout the cycle in case delayed onset diarrhoea occurred. The duration of the treatment cycle varied depending on the chemotherapy regimen, with patients receiving chemotherapy for 1,5 or 14 days at treatment intervals of 2, 3 and 4 weeks. On initiation of the second cycle of chemotherapy with the study drug, patients continued with randomised treatment, self-applying treatment on a daily basis. Active treatment for this second cycle comprised $8 \mathrm{mg}$ transdermal mecamylamine. Doses were selected based on the gastrointestinal side effects observed from previous evaluation of this agent in smoking cessation and functional diarrhoea studies, where increasing incidence of constipation was observed with increasing mecamylamine dose (from around $25 \%$ at $3 \mathrm{mg}$ per day to over $50 \%$ at $8 \mathrm{mg}$ per day in smokers receiving this agent). The overall duration of treatment within the study was two sequential cycles of chemotherapy.

Patients were allowed free access to loperamide or other appropriate anti-diarrhoeal medication on a rescue basis for the duration of any active episodes of diarrhoea. Patients were able to use loperamide at occurrence of diarrhoea at any grade at their own or their physician's discretion. Patients were not allowed concomitant use of anti-diarrhoeal medications other than loperamide, codeine phosphate or octreotide for the duration of the study. Concomitant use of anti-cholinergic agents, including atropine in those patients receiving irinotecan therapy, was not permitted.

Treatment evaluation. Treatment evaluation was based on both physician assessment and patient assessment. For each cycle of chemotherapy, patients' severity of diarrhoea was physicianassessed by NCI grade at the end of the first day of chemotherapy (acute phase) and at the end of the overall cycle of chemotherapy (full cycle). Use of concomitant medications including rescue medications was also recorded.

For each cycle of chemotherapy, patients collected information on a daily basis using two daily diary cards. The first daily diary collected information relating to patients' bowel movements: This included consistency of bowel movements, each graded according to the Bristol Stool Scale (BSS) (Heaton et al, 1992; Lewis and Heaton, 1997); the percentage of days on treatment experiencing loose stools (BSS $>5$ ), the number of episodes of diarrhoea; the mean duration of episodes of diarrhoea (defined as periods of days with more than four bowel movements) and total duration of episodes of diarrhoea. The second diary collected information related to other gastrointestinal symptoms recording these on a daily basis using a four-point scale. These symptoms included nausea, vomiting, constipation, diarrhoea, abdominal pain and abdominal cramps. Additionally, the use of rescue medication in relief of each symptom was also recorded by patients and specifically the number of loperamide or codeine phosphate used daily was also recorded.

Statistical considerations. This was an exploratory study to evaluate the efficacy of mecamylamine in CID hence the level of significance was set at $10 \%$. Assuming an incidence of any grade of CID of $70 \%, 32$ patients in each treatment arm would be required to ensure $90 \%$ statistical power to halve the incidence of diarrhoea with treatment, based on a two-sided $\chi^{2}$ test at the $\alpha=0.1$ level.

The incidence of response (physician-assessed NCI grade responder or partial responder or patient-assessed diary responder) was compared between AGI and placebo using generalised estimating equations with logit link. This was analysed for each time period of assessment (acute phase and full cycle). Effects fitted in the model were treatment and cycle (cycle 1 or 2). The interaction between treatment and cycle was also investigated, and if not significant $(P>0.1)$ was dropped from the model. If the interaction was significant, separate estimates of the treatment effect for each cycle were to be produced. If there was no interaction, then the estimate of the treatment difference would apply across both cycles. The odds ratio (OR) for treatment relative to placebo was calculated with $90 \%$ confidence intervals (CIs).

The mean number of bowel movements a day during each time period of assessment was compared between treatments using mixed models analysis of variance. Effects fitted in the model were treatment and cycle (cycle 1 or 2) and the interaction between treatment and cycle. Estimates of treatment effect were given for each chemotherapy cycle and the results were expressed as the mean difference between treatment and placebo with $90 \%$ CI. The secondary end point measurements were analysed in a similar way.

\section{STUDY END POINTS}

Primary end points. The primary end point was the number of patients who did not experience diarrhoea. This primary end point was measured using two different approaches to defining diarrhoea, first using physician assessment based on NCI CTC grade and second using a patient-reported outcome from data recorded in daily diaries. A responder was a patient who did not experience diarrhoea and was defined by the following criteria: A patient who did not have diarrhoea according to NCI CTC v3.0 grading or a patient who had $\leqslant 4$ bowel movements on all study days of each cycle. Partial responders were defined as those with a reduction of one NCI grade of diarrhoea on treatment. Response was evaluated in two time periods of the first day of chemotherapy (acute phase) and from day 1 to the end of the first cycle of chemotherapy (full cycle).

Secondary end points. A number of secondary end points were derived from the patients' diaries. These included the use of rescue medication (number of loperamide and codeine phosphate tablets used and days of usage) and mean scores for severity of diarrhoea and of other associated symptoms of nausea, vomiting, constipation and abdominal pain and cramps as scored by the patient on an overall severity scale of $0-3(0,1,2$ and 3 representing none, mild, moderate and severe, respectively).

\section{RESULTS}

In all, 64 patients in seven centres in the United Kingdom and Romania were randomised to receive AGI 004 (4 mg then $8 \mathrm{mg}$ per $24 \mathrm{~h}$ ) transdermal patch or placebo for two sequential cycles of chemotherapy.

Baseline patient characteristics. Baseline characteristics were well matched between the two groups (Table 1). The majority of patients had colorectal carcinoma. The most common chemotherapy drugs used were 5-FU or capecitabine, either alone or in combination with other drugs. The proportion of patients receiving the various types of chemotherapy was broadly similar between the 
two groups although there was more use of irinotecan among patients allocated to the placebo arm. There was no significant variation in cycle duration between the two groups but some variation in duration of drug treatment.

Overall, 46 patients $(72 \%)$ had NCI grade 1 diarrhoea prior to study entry, with slightly more of these patients with allocated to the treatment arm $(n=25,78 \%)$ than placebo $(n=21,66 \%)$.

\begin{tabular}{|c|c|c|}
\hline & Active $(n=32)$ & Placebo $(n=32)$ \\
\hline Mean age (range) & $58.9(35-75)$ & $63.4(45-88)$ \\
\hline \multicolumn{3}{|l|}{ Gender } \\
\hline Male & 19 (59\%) & 15 (47\%) \\
\hline Female & $13(41 \%)$ & 17 (53\%) \\
\hline \multicolumn{3}{|c|}{ WHO performance status } \\
\hline 0 & $14(43 \%)$ & $18(56 \%)$ \\
\hline 1 & 17 (53\%) & 14 (43\%) \\
\hline 2 & $1(3 \%)$ & 0 \\
\hline \multicolumn{3}{|l|}{ Tumour type } \\
\hline Colorectal & $14(43 \%)$ & $15(47 \%)$ \\
\hline Breast & $5(16 \%)$ & 7 (22\%) \\
\hline Carcinoid & $1(3 \%)$ & $1(3 \%)$ \\
\hline Gastric & $1(3 \%)$ & $1(3 \%)$ \\
\hline Adrenal & 0 & $1(3 \%)$ \\
\hline Hepatic & 0 & 1 (3\%) \\
\hline Adenocarcinoma & $3(9 \%)$ & $1(3 \%)$ \\
\hline \multicolumn{3}{|l|}{ Drug treatment } \\
\hline FU & $18(56 \%)$ & $13(41 \%)$ \\
\hline Capecitabine & $14(44 \%)$ & $15(47 \%)$ \\
\hline Irinotecan & $2(6 \%)$ & $8(25 \%)$ \\
\hline \multicolumn{3}{|c|}{ Duration of treatment period } \\
\hline 1 day & 0 & $3(9 \%)$ \\
\hline 5 days & 17 (53\%) & 12 (38\%) \\
\hline 14 days & $15(47 \%)$ & 17 (53\%) \\
\hline \multicolumn{3}{|c|}{ Length of treatment cycle } \\
\hline 14 days & 0 & $1(3 \%)$ \\
\hline 21 days & $18(56 \%)$ & 17 (53\%) \\
\hline 28 days & $14(44 \%)$ & 14 (44\%) \\
\hline
\end{tabular}

In total, 18 patients $(28 \%)$ had NCI grade 2 diarrhoea prior to study entry, with seven of these patients allocated to the treatment arm (22\%) and 11 (34\%) allocated to placebo.

Overall compliance with treatment was very good, with a mean level of $90 \%$ in both arms of the study. Two patients in the placebo arm withdrew from the study after randomisation, one by patient choice and another following an adverse event. Additionally, one patient in each arm of the study died during treatment due to disease progression. The remainder of the active treatment arm completed the study.

Response to treatment based on physician assessment. As previously described, patients were classified as responders based on physician assessment of diarrhoea according to NCI grade. Overall, for both the first cycle of chemotherapy $(4 \mathrm{mg}$ per $24 \mathrm{~h}$ dose level) and the second cycle ( $8 \mathrm{mg}$ per $24 \mathrm{~h}$ dose level), a higher proportion of patients in the treatment group than in the placebo group were classified by physician assessment as complete responders (NCI grade 0 ) both for the acute phase (day 1 of the cycle) and for the complete cycle; however, these differences between treatments were not statistically significant (Tables $2 \mathrm{a}$ and 2b). For overall treatment effect, the OR was 1.26 (CI: 0.54-2.93) and this was not statistically significant. Data from the acute phase suggest use of AGI004 doubled the odds of response relative to placebo $(\mathrm{OR}=2.0,90 \% \mathrm{CI}$ : $0.9-4.5)$; however, again this did not reach statistical significance (Table 2a). Similarly, there were greater, but non-significant, differences observed between treatment and placebo at the 8-mg dose level (Tables 2a and 2b). Inclusion of covariates made no significant changes to these results.

Response to treatment based on patient assessment. The second measure of response was based on information obtained from patients' diaries, with a responder defined as a patient reporting $\leqslant 4$ bowel movements per day. Missing data were set at nonresponse. As before, there were more patients classified as responders in the treatment group than the placebo group for both treatment cycles and dose levels (Table 3). Overall, these results suggest a statistically significant treatment effect with an OR of 6.4 (90\% CI: $1.7-24.6, P=0.05)$. At the 4 -mg dose level, the difference between treatment and placebo was not statistically significant; however, at the 8-mg level, the treatment effect did reach significance $(P=0.02)$, with a greater than nine-fold likelihood of response suggested (Table 3 ). Again inclusion of covariates did not alter the observed treatment effect.

Use of rescue medication. Overall, the use of loperamide as rescue medication by patients in the study was low, limiting the statistical analysis that could be performed on this data set. Given this, the

Table 2a. Physician-based assessment of response for the acute phase (day 1)

\begin{tabular}{|c|c|c|c|c|c|}
\hline \multicolumn{6}{|c|}{ Number of patients } \\
\hline Dose & Outcome & AGI004 $(n=32)$ & Placebo $(n=32)$ & $\begin{array}{l}\text { Estimated difference } \\
\text { in response, odds } \\
\text { ratio }(90 \% \mathrm{Cl})\end{array}$ & $P$-value \\
\hline Overall estimate & Responder & & & $1.99(0.88-4.47)$ & 0.16 \\
\hline $4 \mathrm{mg}$ & $\begin{array}{l}\text { Responder } \\
\text { Partial responder } \\
\text { Non-responder }\end{array}$ & $\begin{array}{c}19(59 \%) \\
3(9 \%) \\
10(31 \%)\end{array}$ & $\begin{array}{c}14(44 \%) \\
3(9 \%) \\
14(44 \%)\end{array}$ & $1.94(0.82-4.57)$ & 0.20 \\
\hline $8 \mathrm{mg}$ & $\begin{array}{l}\text { Responder } \\
\text { Partial responder } \\
\text { Non-responder }\end{array}$ & $\begin{array}{c}24(75 \%) \\
0 \\
7(22 \%)\end{array}$ & $\begin{array}{l}17(53 \%) \\
2 \text { (6\%) } \\
9(28 \%)\end{array}$ & $2.05(0.84-5.02)$ & 0.19 \\
\hline
\end{tabular}


Table 2b. Physician-based assessment of response for complete treatment cycle (day 1 until end of cycle)

\begin{tabular}{|c|c|c|c|c|c|}
\hline \multicolumn{6}{|c|}{ Number of patients } \\
\hline Dose & Outcome & AGI004 $(n=32)$ & Placebo $(n=32)$ & $\begin{array}{c}\text { Estimated difference } \\
\text { in response, odds } \\
\text { ratio }(90 \% \mathrm{Cl})\end{array}$ & $P$-value \\
\hline Overall estimate & Responder & & & $1.26(0.54-2.93)$ & 0.65 \\
\hline $4 \mathrm{mg}$ & $\begin{array}{l}\text { Responder } \\
\text { Partial responder } \\
\text { Non-responder }\end{array}$ & $\begin{array}{cl}20 & (63 \%) \\
1 & (3 \%) \\
11 & (34 \%)\end{array}$ & $\begin{array}{r}17(53 \%) \\
4(13 \%) \\
10(31 \%)\end{array}$ & $1.00(0.42-2.38)$ & 1.00 \\
\hline $8 \mathrm{mg}$ & $\begin{array}{l}\text { Responder } \\
\text { Partial responder } \\
\text { Non-responder }\end{array}$ & $\begin{aligned} & 22(69 \%) \\
& 2(6 \%) \\
& 7(22 \%) \\
&\end{aligned}$ & $\begin{array}{c}19(59 \%) \\
1(3 \%) \\
8(25 \%)\end{array}$ & $1.80(0.73-4.43)$ & 0.28 \\
\hline
\end{tabular}

Table 3. Response to treatment based on patient-reported information (using number of bowel movements per day recorded daily by patients)

\begin{tabular}{|c|c|c|c|c|c|}
\hline \multicolumn{6}{|c|}{ Number of patients } \\
\hline Dose & Outcome & AGI004 $(n=32)$ & Placebo $(n=32)$ & $\begin{array}{c}\text { Estimated difference } \\
\text { in response, odds } \\
\text { ratio }(90 \% \mathrm{Cl})\end{array}$ & $\boldsymbol{P}$-value \\
\hline Overall estimate & Responder & & & $6.38(1.65-24.64)$ & 0.05 \\
\hline $4 \mathrm{mg}$ & $\begin{array}{l}\text { Responder } \\
\text { Non-responder }\end{array}$ & $\begin{array}{c}30(94 \%) \\
2(6 \%)\end{array}$ & $\begin{array}{r}26(81 \%) \\
6(19 \%)\end{array}$ & $3.40(0.69-25.11)$ & 0.26 \\
\hline $8 \mathrm{mg}$ & $\begin{array}{l}\text { Responder } \\
\text { Non-responder } \\
\text { No visit }\end{array}$ & $\begin{array}{c}32(100 \%) \\
0 \\
0\end{array}$ & $\begin{array}{c}26(81 \%) \\
3(9 \%) \\
3(9 \%)\end{array}$ & 9.51 (1.72-Not determined) & 0.19 \\
\hline
\end{tabular}

\section{Table 4. Loperamide usage during chemotherapy}

\begin{tabular}{|l|c|c|r|}
\hline Dose & NCl grade & $\begin{array}{c}\text { AGI004 } \\
(\boldsymbol{n}=32)\end{array}$ & $\begin{array}{r}\text { Placebo } \\
(\mathbf{n}=32)\end{array}$ \\
\hline $4 \mathrm{mg}$ & Grade 1 & $6(24 \%)$ & $5(23.8 \%)$ \\
& Grade 2 & $5(71.4 \%)$ & $10(90.9 \%)$ \\
& Total ITT & $11(34.4 \%)$ & $15(46.9 \%)$ \\
\hline $8 \mathrm{mg}$ & Grade 1 & $5(20.0 \%)$ & $3(14.3 \%)$ \\
& Grade 2 & $3(42.9 \%)$ & $7(63.6 \%)$ \\
& Total ITT & $8(25.0 \%)$ & $10(31.3 \%)$ \\
\hline
\end{tabular}

overall usage of loperamide was less in the AGI004 arm than in the placebo arm at both the 4- and 8-mg dose levels with a greater trend observed at the 8-mg dose level (Table 4), specifically in the acute phase (day 1 of chemotherapy) where the difference in loperamide usage between the treatment arm and placebo was significant $(0 \%$ and $12.5 \%(n=4)$, respectively, $P=0.05)$. In the subset of patients with NCI grade 2 diarrhoea, the majority of patients used loperamide with the data suggesting a favourable response to AGI004 in comparison to placebo, again particularly at the 8 -mg dose level, although any interpretation is limited by the small numbers of patients. Similarly, the percentage of days on chemotherapy where rescue medication was used was lower in the treatment arm than placebo, with a mean of $9.7 \%$ in the treatment arm and $13.6 \%$ in the placebo arm at the $4-\mathrm{mg}$ dose level, and $5.6 \%$ and $8.8 \%$ at the $8-\mathrm{mg}$ dose level for AGI004 and placebo, respectively. There was no other rescue medication used other than loperamide for the duration of the study.

Associated symptoms. A number of associated symptoms were also evaluated using information from the patients' daily diaries. Of these, a potential effect of AGI004 on the severity of diarrhoea scores per day of chemotherapy was suggested with a median score of 0.14 and 0.10 per day of chemotherapy for the AGI004 group at the 4- and 8-mg dose level, respectively, in comparison to median scores of 0.33 and 0.21 at the same dose levels for placebo. This difference reached statistical significance at the 8-mg dose level $(P=0.03)$.

Other associated GI symptoms of nausea, vomiting, constipation and abdominal pain or cramps occurred in a limited number of patients in both arms of the study, although no significant differences in these associated symptoms were observed between the two groups.

\section{DISCUSSION}

Chemotherapy-induced diarrhoea remains a significant problem in delivering cytotoxic chermotherapy particularly with agents such as fluoropyrimidines, irinotecan and platinum derivatives. Even with aggressive loperamide treatment after onset of CID, there is still a risk of significant complications or dose delays or reductions following recovery. Hence, there remains a need for preventative measures, and although a number of strategies for CID prevention 
have been previously reported, none has been adopted into routine clinical practice. Studies to date have generally been small and some have been further limited by not including an adequate or any control group (Michael et al, 2004; Rosenoff et al, 2006). Moreover, any potential agent for CID prevention must be well tolerated with a low risk of drug interactions. Therefore, even though a possible role of intestinal alkalisation for CID prevention has been suggested, its usefulness is potentially limited by the changes it causes in the pharmacokinetics and plasma levels of irinotecan (Hamada et al, 2005). A further limiting factor for some preventative agents, despite evidence that they may have a beneficial effect on the incidence or severity of CID, is difficulty in administration, such as need for parenteral administration (Rosenoff et al, 2006; Li et al, 2009), or patient acceptability, particularly in the setting of other treatment toxicities such as nausea or mucositis, which may limit patient compliance with additional oral medication, or potential drug interactions with other medication (Michael et al, 2004).

AGI004 demonstrated effectiveness in reducing chemotherapyassociated diarrhoea, with results suggesting response across multiple measurements of diarrhoea. There were statistically significant response rates both overall $(P=0.05)$ and at the $8-\mathrm{mg}$ dose level $(P=0.02)$, compared with placebo, when using patientreported response data (response defined as $\leqslant 4$ bowel movements on the first day of chemotherapy). The corresponding ORs estimated a six-fold and 10-fold likelihood of response, respectively, compared with placebo. A similar trend was observed when comparing physician-reported outcomes, with use of AGI004 doubling the odds of response relative to placebo $(\mathrm{OR}=2.0,90 \%$ CI: 0.9-4.5) on the first day of chemotherapy; however, this did not reach statistical significance. As this was an exploratory study, evaluation in larger patient numbers would be needed to confirm these treatment effects. Treatment was well tolerated with no drugrelated adverse events, and patients' compliance with treatment was excellent.

In this study, the effect of treatment was assessed using both patient- and physician-reported data, and interestingly a significant treatment effect was observed when using patient-reported data, with a similar but non-significant trend observed when using physician-reported data. Zachariah et al reported the use of patientbased assessments in conjunction with physician assessment based on NCI CTC grading in prevention of chemoradiation-induced diarrhoea however other studies of CID prevention have not reported using both methods of treatment evaluation as primary end points, with most reporting results based on physician assessment by NCI grade (Michael et al, 2004; Sergio et al, 2008; Li et al, 2009). In this study, information obtained from patients' diaries in which patients recorded the required study outcome measures on a daily basis was used as a primary outcome measure, which may be a more true record of chemotherapy toxicity given symptoms are recorded contemporaneously rather than after the treatment cycle is complete when toxicity may have resolved or for longer treatment cycles patients' recall may be less accurate. Interestingly, in the prospective randomised study of octreotide for prevention of chemoradiationinduced diarrhoea, Zachariah et al, 2010 also examined both physician-reported and patient-reported data for response assessment, specifically using three previously validated bowel function assessment tools, and found no significant differences in their comparison of these tools. A statistically significant correlation between these tools and the physician-reported grade of diarrhoea was also identified. Hence, using patient-reported data for treatment evaluation appears to be a valid approach regardless of the specific diary tool used; however, it is still relevant to include physician assessment as well to try and further validate the correlation between physician and patient assessment.

This was an exploratory study to assess the efficacy of AGI004 in controlling CID, and is limited by sample size. Clearly, given the response rates based on physician assessment of NCI grade of diarrhoea observed in this study, a larger sample size would have been required to show a significant difference between treatment and placebo. Moreover, the small sample size, in particular, the low numbers of patients with more severe diarrhoea (NCI grade 2) may have limited the effect of treatment observed in this study both overall and in this more severely affected population. Similarly, the potential treatment effect may also have been limited by the relatively small number of patients receiving irinotecan either as monotherapy or in combination with a fluoropyrimidine, a high risk group for development of CID and the target population of several previous studies of anti-diarrhoeal agents (Takeda et al, 2001; Michael et al, 2004).

Overall, however, the ease of use of transdermal AGI004, the lack of adverse events and the evidence of efficacy in reducing CID suggest that this may be a potential new approach for prevention of CID and further evaluation of this agent in the management of CID is warranted, particularly in higher risk groups such as patients with gastrointestinal malignancies receiving irinotecan/ fluoropyrimidine chemotherapy.

\section{REFERENCES}

Barbounis V, Koumakis G, Vassilomanolakis M, Demiri M, Efremidis AP (2001) Control of irinotecan-induced diarrhea by octreotide after loperamide failure. Support Care Cancer 9: 258-260.

Benson 3rd AB, Ajani JA, Catalano RB, Engelking C, Kornblau SM, Martenson Jr JA, McCallum R, Mitchell EP, O’Dorisio TM, Vokes EE, Wadler S (2004) Recommended guidelines for the treatment of cancer treatment-induced diarrhea. J Clin Oncol 22: 2918-2926.

Boige V, Mendiboure J, Pignon JP, Loriot MA, Castaing M, Barrois M, Malka D, Tregouet DA, Bouche O, Le Corre D, Miran I, Mulot C, Ducreux M, Beaune P, Laurent-Puig P (2010) Pharmacogenetic assessment of toxicity and outcome in patients with metastatic colorectal cancer treated with LV5FU2, FOLFOX, and FOLFIRI: FFCD 2000-05. J Clin Oncol 28: 2556-2564.

Braun MS, Richman SD, Thompson L, Daly CL, Meade AM, Adlard JW, Allan JM, Parmar MK, Quirke P, Seymour MT (2009) Association of molecular markers with toxicity outcomes in a randomized trial of chemotherapy for advanced colorectal cancer: the FOCUS trial. J Clin Oncol 27: 5519-5528.

Cascinu S, Bichisao E, Amadori D, Silingardi V, Giordani P, Sansoni E, Luppi G, Catalano V, Agostinelli R, Catalano G (2000) High-dose loperamide in the treatment of 5-fluorouracil-induced diarrhea in colorectal cancer patients. Support Care Cancer 8: 65-67.

Duncan M, Grant G (2003) Oral and intestinal mucositis-causes and possible treatments. Aliment Pharmacol Ther 18: 853-874.

Furness JB, Sanger GJ (2002) Intrinsic nerve circuits of the gastrointestinal tract: identification of drug targets. Curr Opin Pharmacol 2: 612-622.

Giacchetti S, Perpoint B, Zidani R, Le Bail N, Faggiuolo R, Focan C, Chollet P, Llory JF, Letourneau Y, Coudert B, Bertheaut-Cvitkovic F, LarregainFournier D, Le Rol A, Walter S, Adam R, Misset JL, Levi F (2000) Phase III multicenter randomized trial of oxaliplatin added to chronomodulated fluorouracil-leucovorin as first-line treatment of metastatic colorectal cancer. J Clin Oncol 18: 136-147.

Gibson RJ, Keefe DM (2006) Cancer chemotherapy-induced diarrhoea and constipation: mechanisms of damage and prevention strategies. Support Care Cancer 14: 890-900.

Goumas P, Naxakis S, Christopoulou A, Chrysanthopoulos C, Nikolopoulou VV, Kalofonos HP (1998) Octreotide acetate in the treatment of fluorouracil-induced diarrhea. Oncologist 3: 50-53.

Hamada A, Aoki A, Terazaki H, Ito K, Yokoo K, Sasaki Y, Saito H (2005) Pharmacokinetic changes of irinotecan by intestinal alkalinization in an advanced colorectal cancer patient. Ther Drug Monit 27: 536-538.

Heaton KW, Radvan J, Cripps H, Mountford RA, Braddon FE, Hughes AO (1992) Defecation frequency and timing, and stool form in the general population: a prospective study. Gut 33: 818-824.

Leichman CG, Fleming TR, Muggia FM, Tangen CM, Ardalan B, Doroshow JH, Meyers FJ, Holcombe RF, Weiss GR, Mangalik A et al. (1995) Phase II study of fluorouracil and its modulation in advanced 
colorectal cancer: a Southwest Oncology Group study. J Clin Oncol 13: 1303-1311.

Lewis SJ, Heaton KW (1997) Stool form scale as a useful guide to intestinal transit time. Scand J Gastroenterol 32: 920-924.

Li Y, Ping X, Yu B, Liu F, Ni X, Li J (2009) Clinical trial: prophylactic intravenous alanyl-glutamine reduces the severity of gastrointestinal toxicity induced by chemotherapy-a randomized crossover study. Aliment Pharmacol Ther 30: 452-458.

McLeod HL, Sargent DJ, Marsh S, Green EM, King CR, Fuchs CS, Ramanathan RK, Williamson SK, Findlay BP, Thibodeau SN, Grothey A, Morton RF, Goldberg RM (2010) Pharmacogenetic predictors of adverse events and response to chemotherapy in metastatic colorectal cancer: results from North American Gastrointestinal Intergroup Trial N9741. J Clin Oncol 28: 3227-3233.

Meropol NJ, Blumenson LE, Creaven PJ (1998) Octreotide does not prevent diarrhea in patients treated with weekly 5 -fluorouracil plus high-dose leucovorin. Am J Clin Oncol 21: 135-138.

Michael M, Brittain M, Nagai J, Feld R, Hedley D, Oza A, Siu L, Moore MJ (2004) Phase II study of activated charcoal to prevent irinotecan-induced diarrhea. J Clin Oncol 22: 4410-4417.

Papke RL, Sanberg PR, Shytle RD (2001) Analysis of mecamylamine stereoisomers on human nicotinic receptor subtypes. J Pharmacol Exp Ther 297: 646-656.

Rose JE, Behm FM, Westman EC, Levin ED, Stein RM, Ripka GV (1994) Mecamylamine combined with nicotine skin patch facilitates smoking cessation beyond nicotine patch treatment alone. Clin Pharmacol Ther 56: 86-99.

Rosenoff SH, Gabrail NY, Conklin R, Hohneker JA, Berg WJ, Warsi G, Maloney J, Benedetto JJ, Miles EA, Zhu W, Anthony L (2006) A multicenter, randomized trial of long-acting octreotide for the optimum prevention of chemotherapy-induced diarrhea: results of the STOP trial. J Support Oncol 4: 289-294.

Rothenberg ML, Meropol NJ, Poplin EA, Van Cutsem E, Wadler S (2001) Mortality associated with irinotecan plus bolus fluorouracil/leucovorin: summary findings of an independent panel. J Clin Oncol 19: 3801-3807.

Saltz LB, Cox JV, Blanke C, Rosen LS, Fehrenbacher L, Moore MJ, Maroun JA, Ackland SP, Locker PK, Pirotta N, Elfring GL, Miller LL (2000) Irinotecan plus fluorouracil and leucovorin for metastatic colorectal cancer. Irinotecan Study Group. N Engl J Med 343: 905-914.
Sergio GC, Felix GM, Luis JV (2008) Activated charcoal to prevent irinotecaninduced diarrhea in children. Pediatr Blood Cancer 51: 49-52.

Szilagyi A, Shrier I (2001) Systematic review: the use of somatostatin or octreotide in refractory diarrhoea. Aliment Pharmacol Ther 15: 1889-1897.

Takeda Y, Kobayashi K, Akiyama Y, Soma T, Handa S, Kudoh S, Kudo K (2001) Prevention of irinotecan (CPT-11)-induced diarrhea by oral alkalization combined with control of defecation in cancer patients. Int $J$ Cancer 92: 269-275.

Valenti Moreno V, Brunet Vidal J, Manzano Alemany H, Salud Salvia A, Llobera Serentill M, Cabezas Montero I, Servitja Tormo S, Sopena Bert E, Guma Padro J (2006) Prevention of irinotecan associated diarrhea by intestinal alkalization. A pilot study in gastrointestinal cancer patients. Clin Transl Oncol 8: 208-212.

Van Cutsem E, Findlay M, Osterwalder B, Kocha W, Dalley D, Pazdur R, Cassidy J, Dirix L, Twelves C, Allman D, Seitz JF, Scholmerich J, Burger HU, Verweij J (2000) Capecitabine, an oral fluoropyrimidine carbamate with substantial activity in advanced colorectal cancer: results of a randomized phase II study. J Clin Oncol 18: 1337-1345.

Ychou M, Douillard JY, Rougier P, Adenis A, Mousseau M, Dufour P, Wendling JL, Burki F, Mignard D, Marty M (2000) Randomised comparison of prophylactic antidiarrheal treatment versus no prophylactic antidiarrheal treatment in patients receiving CPT-11 (irinotecan) for advanced 5-FU-resistant colorectal cancer: an open-label multicenter phase II study. Am J Clin Oncol 23: 143-148.

Young JM, Shytle RD, Sanberg PR, George TP (2001) Mecamylamine: new therapeutic uses and toxicity/risk profile. Clin Ther 23: 532-565.

Zachariah B, Gwede CK, James J, Ajani J, Chin LJ, Donath D, Rosenthal SA, Kane BL, Rotman M, Berk L, Kachnic LA (2010) Octreotide acetate in prevention of chemoradiation-induced diarrhea in anorectal cancer: randomized RTOG trial 0315. J Natl Cancer Inst 102: $547-556$.

This work is published under the standard license to publish agreement. After 12 months the work will become freely available and the license terms will switch to a Creative Commons AttributionNonCommercial-Share Alike 3.0 Unported License. 